\title{
Corporate social responsibility in a game-theoretic context
}

\author{
Luciano Fanti ${ }^{1} \cdot$ Domenico Buccella ${ }^{2}$
}

Received: 6 April 2016/Revised: 2 November 2016/Accepted: 15 November 2016/

Published online: 2 December 2016

(C) The Author(s) 2016. This article is published with open access at Springerlink.com

\begin{abstract}
Using a simple Cournot duopoly model with differentiated products, this work studies the firms' strategic choice of whether to adopt Corporate Social Responsibility (CSR) rules. The proposed game-theoretic approach shows that, depending on the degree of product differentiation and firms' social concern, different equilibria arise: (1) all firms in the industry follow CSR rules, (2) all firms are profit-maximising (PM), (3) asymmetric equilibria are present (one CSR firm, one PM firm), and (4) multiple symmetric equilibria are present. Under Bertrand competition, universal PM is the unique equilibrium in which the social welfare is the least desirable: this implies that, in contrast to the conventional wisdom, Bertrand may appear as welfare dominated by Cournot. This work can help to explain the widely observed phenomenon, in the real world, of different industries in which firms' CSR behaviours are more or less commonly widespread.
\end{abstract}

Keywords CSR · Cournot duopoly · Profitability

Electronic supplementary material The online version of this article (doi:10.1007/s40812-016-0064-3) contains supplementary material, which is available to authorized users.

We are extremely grateful to an Associate Editor of this Journal and two anonymous referees for their comments and suggestions that have substantially contributed to the improvement of the quality of this paper. Usual disclaimer applies.

Domenico Buccella

buccella@kozminski.edu.pl

Luciano Fanti

lfanti@ec.unipi.it

1 Department of Economics and Management, University of Pisa, Via Cosimo Ridolfi, 10, 56124 Pisa (PI), Italy

2 Department of Economics, Kozminski University, Jagełłonska Street, 57/59, 03301 Warsaw, Poland 
JEL Classification D21 $\cdot$ L13 $\cdot$ L14 $\cdot$ M14

\section{Introduction}

The increasing presence of firms adopting Corporate Social Responsibility (CSR) behaviours has been observed worldwide. Indeed, according to KPMG, CSR behaviours are surely a dominant global business practice: in $2015,73 \%$ of the top 100 companies surveyed in 45 countries have reported the realisation of CSR activities, demonstrating an increase of 9 percentage points since 2011, when $64 \%$ of the companies surveyed had issued CRS reports. Moreover, $92 \%$ of the 250 Global Fortune Index companies, the world's 250 largest companies, have performed CSR actions (KPMG 2011, 2015).

The economic literature has recently tried to offer explanations, usually beyond the standard short-term profit maximization, to justify the growth of this phenomenon (e.g. Benabou and Tirole 2010). Nonetheless, it is widely observed that firms adopting CSR may present extremely different levels of engagement in their "socially concerned" activities; moreover, the simultaneous presence of both CSR and non-CSR firms within the same industry occurs. For example, according to the Reputation Institute (2015), in the automotive sector, two German carmakers, BMW and Daimler, rank among the top 10 companies with the best CSR reputation (1st and 3rd place, respectively) with respect to the Japanese Toyota (35th) and Honda Motor (61st), US companies Ford (65th) and General Motors (96th), and the absence of the top 100 ranked companies of other giants in the industry such as French companies Renault and PSA Peugeot Citroën, Korean manufacturers KIA and Hyundai, and the FCA Group.

This fact is not immediately intuitive and promptly explained. It can be easily shown (as this work does) that a firm, in most cases, may not have any convenience in following CSR rules (for example, taking care of the consumers' welfare), because profits would be reduced in the case of oligopoly. Hence, if the adoption of CSR rules is unprofitable, it is puzzling to explain the widespread (although not universal) presence of a socially concerned firm in several industries (unless not strictly profit maximizing reasons are considered).

The present paper contributes by providing an explanation in "strategic" terms of the multi-faceted phenomenon of CSR and complementing the different perspectives already identified in the recent industrial organization literature. One line of research in economics recognizes CSR as private provision of public goods and private elimination of a public bad (Bagnoli and Watts 2003; Kotchen 2006; Besley and Ghatak 2007). A second line of the research has focused on the motives that lead companies to adopt CSR behaviours (Baron 2001, 2009; Porter and Kramer 2006; García-Gallego and Georgantzís 2009; Reinhardt and Stavins 2010; Benabou and Tirole 2010; Lambertini and Tampieri 2010; Kopel and Brand 2012). In particular, the contributions of Baron $(2001,2009)$ highlight that companies may strategically follow CSR rules simply guided by their pure selfishness, where CSR is a response to social pressure directly exerted by social activists-e.g. such as NonGovernmental Organizations (NGOs), defined by Baron (2001) as actors in "private politics" - especially through threats (boycotting, negative propaganda) or rewards (endorsements). Moreover, according to Baron (2009), NGOs can also distinguish 
between morally motivated CSR and CSR induced by social pressure, and thus they tend to target their campaign against morally managed firms, because they are more vulnerable to the campaign than the self-interested firms. On the other hand, from the view of Benabou and Tirole (2010), CSR is a pro-social behaviour resulting from several interacting motivations, from pure altruism to material motivation, social and self-esteem concerns. Moreover, as argued by Reinhardt and Stavins (2010), among others, CSR may be a strategy like any other form of product differentiation if there are customers-identifiable by firms-willing to pay for ethical goods which may be profitable: the opportunity arises, for instance, because of the presence of asymmetric information, economies of scale, intellectual-property protection, and the successful defense of the resultant niche against imitators, according to basic economics. More interestingly, García-Gallego and Georgantzís (2009) consider the role of the "pressure" exerted by heterogeneous consumers in a vertically differentiated duopoly with firms' strategic choice of their degree of corporate social responsibility. Those authors study the effects of an increase in consumers' willingness to pay for products sold by socially responsible manufacturers. The consumers' preferences towards CSR behaviours increase the demand; however, a trade-off exists because the adoption of CSR rules implies a quadratic cost. They find that shifting towards socially responsible consumer preferences is, in most cases, welfare-improving. Conversely, it can be welfare-reducing when such an increase changes the market structure. Therefore, the above-mentioned literature, and in particular García-Gallego and Georgantzís (2009), examine the demand-side (the consumers' or NGOs) CSR preferences while the current work focuses on the supply-side (the firms') CSR preferences in the sense that supplied quantities are chosen by firms to maximise also consumers' interests. Moreover, in a recent paper to appear in this journal, Fanti and Buccella (2016) investigate the effect that the incumbent's CSR adoption can have on a potential entrant decision. On the other hand, the appearance of universal adoption of CSR behaviours in an industry, leading to a "prisoner's dilemma" situation, has been identified by Kopel and Brand (2012), which seems to be the unique paper dealing with this strategical analysis, to the best of the authors' knowledge.

In the current paper, we examine if a correct game-theoretic approach to this issue may explain the above-mentioned stylised facts; that is, the emergence of different equilibria in different industries (i.e. all firm adopt CSR rules, all firms do not follow CSR rules or asymmetric equilibria). Making use of a simple Cournot duopoly model with identical firms and differentiated products, we show that the strategic nature of the adoption of CSR rules may explain the occurrence in the equilibrium of situations in which (1) both firms follows CSR rules, (2) both firms do not follow CSR rules, (3) asymmetric equilibria in which one firm adopts CSR while the rival does not, and (4) multiple symmetric equilibria in which both firms may decide whether to adopt CSR, depending on the degree of product differentiation.

On the other hand, in the case of a Bertrand duopoly (analysed in the "Appendix"), we find that profit maximization is the dominant strategy for firms. In other words, unilateral deviation from the profit maximisation rule is always unprofitable for firms. The rationale for this result is rather intuitive: given that 
under Bertrand the nature of competition is in strategic complements, the unilateral adoption of CSR behaviours (taking care of consumers' surplus) leads the firm to produce a larger amount of output than the rival, with a negative impact on the firm's price and profits. However, in the presence of strategic complements with complement goods, if the social concern is not too strong, there is an area in the parameter space in which the overall adoption of CSR rules payoff-dominates the profit maximisation equilibrium; that is, firms are cast into a classical prisoner's dilemma game.

We find that the adoption of CSR rules always implies a more intensive product market competition, under both the Cournot and Bertrand conjectures. However, the role of the product differentiation is crucial. Under Cournot competition, with substitute goods, the reaction functions have a standard downward sloping shape: goods are strategic substitutes. In the presence of complement goods, the reaction functions become upward sloping, and goods behave as when strategic complements. In both cases, the increasing weight attached to the stakeholder-consumers' interests leads the socially concerned firms to an aggressive market behaviour via output expansion, which is stronger with substitute than with complement products. On the other hand, under Bertrand competition, with substitute goods, the reaction functions are upward sloping (strategic complements), while with complement goods, the reaction functions become downward sloping, and goods behave as when strategic substitutes. Also in these cases, an increase of the social concern level yields aggressive product market behaviour of the CSR firm through a price reduction, which is more intense with complements than substitute products. Thus, these results may be of great interest for the current policy debate on firms' social concern.

Concerning social welfare, under Cournot competition, the firms' strategic interaction leads to the most desirable welfare outcome ${ }^{1}$, when the goods are sufficiently substitutes and sufficiently complements and, in particular, if the level of social concerns are adequately low. However, while the former case is in contrast to firms' interests, in the latter case the firms' and social interests coincide. Therefore, when the emergent equilibrium is the best achievable and the interests of all the agents (both firms, consumers and social welfare as a whole) coincide, the best achievable outcome can be also defined as the Pareto-superior outcome. Nonetheless, there is a wide area of the relevant parameter space characterised by low-medium degrees of goods' substitutability/complementarity in which universal

\footnotetext{
${ }^{1}$ In this paper, we have carried out a welfare analysis in which we have compared the social welfare under the three configurations arising from the firms' game, that is, universal CSR, universal PM or one firm adopting CSR and one firm profit maximizing. Thus, for simplicity, we have defined, loosely speaking, the first position in the social welfare ranking as "the best achievable welfare outcome", the second position in the ranking as the "second best achievable outcome" and, finally, the third position as the "third best achievable outcome". Notice that, as a referee has pointed out, as long as there is imperfect competition in the product market, the first best outcome cannot be reached. In this context, the case that would approach the first best is universal CSR, but only for the particular case in which the parameter measuring the social concerns is equal to $k=1$. Finally, we have defined the cases in which the sub-game perfect Nash equilibrium of the game between firms is payoff-dominant as Pareto-efficient with respect to another equilibrium, and when it is payoff-dominated by another equilibrium as Pareto-inefficient.
} 
profit maximisation arises as endogenous equilibrium, driving the economy to the third best achievable social welfare outcome.

On the other hand, in the case of Bertrand competition, product market interactions always determine the rise of universal profit maximisation as endogenous equilibrium, and this outcome generates the third best achievable outcome in terms of welfare for a wide set of the parameter space.

The remainder of the paper is organized as follows. Section 2 presents the basic ingredients of the duopoly model, with firms deciding whether to adopt CSR rules. Section 3 describes the analysis of the game equilibria. Section 4 discusses the implications in terms of social welfare. Finally, Sect. 5 concludes with a brief discussion of the main results and an outline of the future research directions.

\section{The model}

We assume that firms produce heterogeneous goods. As usual, the standard linear inverse market demand is as follows

$$
p_{i}=a-q_{i}-\gamma q_{j}
$$

where $p$ denotes price, $q_{i}$ and $q_{j}$ are the firms' output levels for $i, j=1,2$ and $i \neq j$ and $-1<\gamma \leq 1$. Note that, if $\gamma<0(>0)$, then products are complements (substitutes) (if $\gamma=0$, goods are completely differentiated and each firm is a monopolist for its own product). For tractability, we assume that both firms have zero production costs. ${ }^{2}$

\subsection{Both firms follow CSR rules}

Following the recent established literature (e.g. Goering 2007, 2008; Lambertini and Tampieri 2010), we consider in our model that all social concerns can be interpreted as part of consumer surplus; thus, the feature of a CSR firm is to be sensitive to it. Therefore, we suppose that the firm, in its objective, wishes to maximize profits plus a fraction of the market consumer surplus $k$, the firm's social concern or care for consumer outcomes in the market. Therefore, the stakeholders' participation in governance applies regarding market decisions. That is, stakeholders exercise "pressure" with regard to the firm's objective, while private owners make the company's strategic choices. As a consequence, in the current model, the firms' strategic choice is whether to adopt CSR rules. On the other hand, the stakeholders, once involved in the firm's governance, fix the level of social engagement. Therefore, when a firm decides to be socially responsible, the level of social concern $k$ is taken as exogenously given by the private owners. In other words, the owners of the firms can make a binary choice: either $k=0$ in the case of profit maximisation or a given positive $k$ in the case of CSR rules adoption (where $k$ is exogenously given, for instance, by the customary toughness of the stakeholders incorporated in

\footnotetext{
${ }^{2}$ This does not imply any loss of generality, in that, under symmetric linear costs, all of the paper's results are unchanged.
} 
the firm's objective function). This is coherent with the results of the empirical study of Spitzeck and Hansen (2010), who find that the stakeholder engagement mechanism is mainly confined to "dialogue and issues" advisory, while the structural strategic choices (i.e. different from the output choices) of the company are outside their sphere. Moreover, given that the firms compete for the same clients in the industry, it can be reasonably assumed that the level of social engagement stakeholders request is identical for both companies.

It follows that the objective function of the firm following CSR rules can be specified as a simple parameterised combination of profits and consumer surplus. Profits and consumer surplus are, respectively:

$$
\begin{gathered}
\pi_{i}=\left(a-q_{i}-\gamma q_{j}\right) q_{i} \\
C S=\frac{\left(q_{i}^{2}+q_{j}^{2}+2 \gamma q_{i} q_{j}\right)}{2}
\end{gathered}
$$

Thus, the CSR objective function $(W)$ is

$$
W_{i}=\pi_{i}+k C S=\left(a-q_{i}-\gamma q_{j}\right) q_{i}+k \frac{\left(q_{i}^{2}+q_{j}^{2}+2 \gamma q_{i} q_{j}\right)}{2}
$$

where $k \in[0,1]$ denotes the weight that CSR firm assigns to consumer surplus. ${ }^{3}$

The analysis is carried as usual through the maximisation of (4) with respect to the quantity, which leads to the two reaction functions

$$
q_{i}\left(q_{j}\right)=\frac{a-\gamma q_{j}(1-k)}{2-k}
$$

for $i, j=1,2$, and $i \neq j$. Solving the system in (5), one gets the equilibrium output

$$
q=\frac{a}{2-k+\gamma(1-k)}
$$

Substituting (6) backwards, we obtain the equilibrium profits ${ }^{4,5}$

$$
\pi^{C S R / C S R}=\frac{a^{2}[1-k(1+\gamma)]}{[2-k+\gamma(1-k)]^{2}} .
$$

Note that the satisfaction of the non-negativity constraint on profits requires ultimately ${ }^{6}$ that $k \leq \frac{1}{1+\gamma} \equiv k^{\mathrm{T}}$ (that is, the firm's interest for the consumer's welfare

\footnotetext{
${ }^{3}$ Goering $(2007,2008)$ ascribes this objective function also to non-profit organizations (NPO), which compete in commercial markets, for instance in sectors including university bookstores (Schiff and Weisbrod 1991), water utility, rail track maintenance company, private air-traffic control organization (Bennett et al. 2003), and even the high-tech markets (Benz 2005). Thus, commercial NPOs selling their output and services, which provide them revenues, can be considered CSR firms as well.

${ }^{4}$ Henceforth, the first (resp. second) apex denotes the choice of the firm 1 (resp. 2).

${ }^{5}$ Note that the values related to the case of profit maximising firms can be immediately derived by setting $k=0$ in the expressions of quantity and profits. For economy of space, those are not reported in the main text.

${ }^{6}$ In fact, it can be easily observed that the equilibrium quantity (6) is positive for any $k \in[0,1]$.
} 
has not to be too high, especially if there is a fierce product competition). This upper bound, however, is not relevant in the case of $\gamma<0$ : in fact, when goods are complements, profits are positive for any $k \in[0,1]$. We assume that this inequality (which is also the most stringent) holds true for the rest of the paper.

\subsection{The asymmetric case: one firm follows CSR rules, while the other is profit-maximising}

Let us consider the case that firm $i$ maximises the social objective function (CSR), while the rival $j$ maximises profits (PM).

Hence, firm $i$ maximises (4) with respect to the quantity, obtaining the usual reaction function (5). On the other hand, firm $j$ maximises its profit function (2), and thus the FOCs for firm $j$ determine the following reaction function:

$$
q_{j}\left(q_{i}\right)=\frac{a-\gamma q_{i}}{2}
$$

Solving the system composed by (5) and (8) for the firms' quantities, we obtain firm $i$ 's output and firm $j$ 's output, respectively:

$$
\begin{aligned}
q_{i} & =\frac{a[2-\gamma(1-k)]}{2(2-k)-\gamma^{2}(1-k)} \\
q_{j} & =\frac{a[2-\gamma-k]}{2(2-k)-\gamma^{2}(1-k)}
\end{aligned}
$$

By substituting (9) and (10) in (2), we find the following equilibrium profits of the mixed case:

$$
\begin{gathered}
\pi_{i}^{C S R / P M}=\frac{a^{2}[2-\gamma(1-k)]\left[\gamma^{2} k-\gamma+2(1-k)\right]}{\left[2(2-k)-\gamma^{2}(1-k)\right]^{2}} \\
\pi_{j}^{C S R / P M}=\frac{a^{2}(2-\gamma-k)^{2}}{\left[2(2-k)-\gamma^{2}(1-k)\right]^{2}}
\end{gathered}
$$

Now we are in a position to derive which rule (CSR or profit-maximising) endogenously emerges as SPNE for both firms.

\subsection{The role of CSR on firms' reaction functions}

At this point, in the spirit of Bulow et al. (1985), a short digression may provide further details on the strategic effects that the adoption of CSR rules has on firms' reaction functions. ${ }^{7}$

\footnotetext{
7 As known, according to the pioneering work of Bulow et al. (1985), decisions are strategic substitutes under Cournot competition and strategic complements under Bertrand competition. Formally, let $a_{i}$ denote firm $i$ 's action such as quantity or price decisions, and let $\pi_{i}\left(a_{i}, a_{j}\right)$ be the profit function of firm $i$ when it takes action $a_{i}$ and the rival, firm $j$, takes action $a_{j}$. Then, strategic substitutes are defined as $\frac{\partial \pi_{i}^{2}}{\partial a_{i} \partial a_{j}}<0$, while strategic complements are defined as $\frac{\partial \pi_{i}^{2}}{\partial a_{i} \partial a_{j}}>0$.
} 

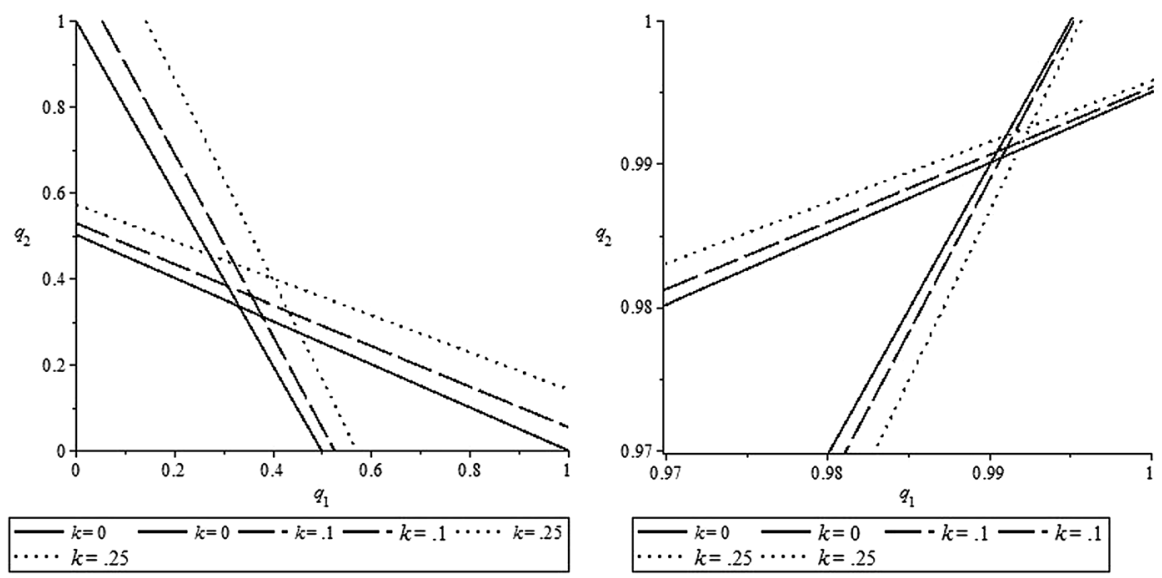

Fig. 1 Adoption of different levels of social engagement (CSR rules) and firms' reaction functions. Left box perfect substitutes $(\gamma=1)$. Right box almost perfect complements $(\gamma=-.99)$. The graphs are drawn for $a=1$

It is easy to see from the reaction functions (5) and (8) that a socially concerned firm has an incentive to offer a level of output larger than a profit-maximising firm. Irrespective of the value of $\gamma$, as the intensity of the social concerns $(k)$ rises, the output of the CSR firm expands as well. In fact, the differentiation of (5) and (8) shows that $\frac{\partial q_{i}}{\partial k}>0$, no matter goods are substitutes $(\gamma>0)$ or complements $(\gamma<0)$.

Figure 1 depicts this result. The left box shows the case of substitute goods: the reaction functions are downward sloping; i.e. we are in the presence of goods which are strategic substitutes. On the other hand, the right box depicts the case of complement goods: the reaction functions are upward sloping and the goods behave as when the strategies are complements. In both cases, the adoption of CSR rules and the increasing weight attached to the stakeholder-consumers' interests lead the firms to demonstrate more aggressive market behaviour through output expansion, even though the relative aggressiveness is stronger when goods are substitutes than complements (the output expansion for a given level of $k$ is larger when $\gamma>0$ than when $\gamma<0$ ). As a consequence, the effect of following CSR behaviours is that of accelerating product market competition, in the vein of the delegation games' logic with managers (e.g. Fershtman and Judd 1987).

\section{The game analysis}

Let us define the following profit differentials:

\footnotetext{
Footnote 7 continued

For instance, CSR represents a commitment on the decision variables which plays a different strategic role depending on the competition mode, as in the case of forward market: with regard to Cournot competition, see Allaz and Vila (1993), while for Bertrand, see Mahenc and Salanié (2004).
} 


$$
\begin{gathered}
\Delta \pi_{1}=\pi_{1}^{C S R / P M}-\pi^{P M / P M} \\
=\frac{a^{2} k(1+\gamma)\left[(k-1) \gamma^{4}+2 \gamma^{3} k+4 \gamma^{2}-4 \gamma k-4 k\right]}{\left[2(2-k)-\gamma^{2}(1-k)\right]^{2}(2+\gamma)^{2}} \frac{>}{<} 0 \\
\Leftrightarrow k \frac{<}{>} k^{\circ}=\frac{\gamma^{2}\left(4-\gamma^{2}\right)}{4(\gamma+1)-2 \gamma^{3}-\gamma^{4}} \\
\Delta \pi_{2}=\pi_{2}^{C S R / P M}-\pi^{C S R / C S R} \\
=\frac{a^{2} k(1+\gamma)\left[(k-1)^{2} \gamma^{4}-\gamma^{2}\left(4+2 k^{2}-6 k\right)-(\gamma-1)\left(4 k^{2}-k^{3}-4 k\right)\right]}{\left[2(2-k)-\gamma^{2}(1-k)\right]^{2}[2-k-\gamma(1-k)]^{2}}-\frac{>}{<} \\
\Leftrightarrow k \frac{>}{<} k^{*}(\gamma)
\end{gathered}
$$

$$
\begin{aligned}
\Delta \pi_{3} & =\pi^{P M / P M}-\pi^{C S R / C S R}=\frac{a^{2} k(1+\gamma)\left[\gamma^{2}+\gamma(k+2)+k\right]}{[2+k-\gamma(1-k)]^{2}(2+\gamma)^{2}} \frac{>}{<} 0 \Leftrightarrow k \frac{<}{>} k^{\circ \circ} \\
& =-\frac{\gamma(2+\gamma)}{1+\gamma} .
\end{aligned}
$$

$\Delta \pi_{1}$ describes the gain or loss of being social responsible rather than PM, given that the rival is PM. On the other hand, $\Delta \pi_{2}$ defines the gain or loss of being socially responsible rather than PM, given that the rival adopts CSR rules ${ }^{8}$. Finally, $\Delta \pi_{3}$ describes the gain or loss of the overall PM rule in the industry rather than the universal adoption of social responsible behaviours.

First, we analyse the usual case of homogeneous product.

Perfect substitutes goods, i.e. $\gamma=1$.

Result 1 Given that $\Delta \pi_{1}>0, \Delta \pi_{2}>0=0$ for $k \frac{>}{<} k^{*}=0.323$ and $k^{\mathrm{T}} \leq \frac{1}{1+\gamma}$, (1) if $k<k^{*}$ then there exists a unique sub-game perfect Nash equilibrium (SPNE), that is (CSR, CSR), and since (PM, PM) payoff-dominates (CSR, CSR), it is Paretoinefficient, so that a standard prisoner's dilemma emerges; (2) if $k \in\left[k^{*}, k^{\mathrm{T}}\right]$ then there exist two pure-strategy asymmetric Nash equilibria, that is (CSR, PM) and (PM, CSR), and the game becomes a coordination game. In addition, the asymmetric equilibrium (CSR, PM) payoff-dominates (CSR, CSR), while (PM, $\mathrm{CSR})$ is payoff-dominated by (PM, PM).

Proof The proof is directly derived from (1), profit differentials (13), (14), and (15), and (2) the two pure-strategy asymmetric Nash equilibria follow from the firms' payoff structure in $k \in\left[k^{*}, k^{\mathrm{T}}\right]: \pi_{1}^{C S R / P M}>\pi^{P M / P M}>\pi_{2}^{C S R / P M}>\pi^{C S R / C S R}$, while the payoff-dominance of (PM, PM), that is $2 \pi^{P M / P M}>\pi_{1}^{C S R / P M}+\pi_{2}^{C S R / P M}$, is shown by direct comparison.

\footnotetext{
${ }^{8} k^{*}(\gamma)$ cannot be presented in closed form; however, it is easily obtained through numerical and graphical calculations.
} 
Fig. 2 Plot of the profit differentials [Eqs. (13), (14), and (15)] in the $(\gamma, k)$-space. The graphs are drawn for $a=1$, $\Delta \pi_{1}=0$ (black solid line $)$, $\Delta \pi_{2}=0$ (red dotted line), $\Delta \pi_{3}=0$ (blue dotted-dashed line $), \pi_{1}=0$ (solid green line $)$

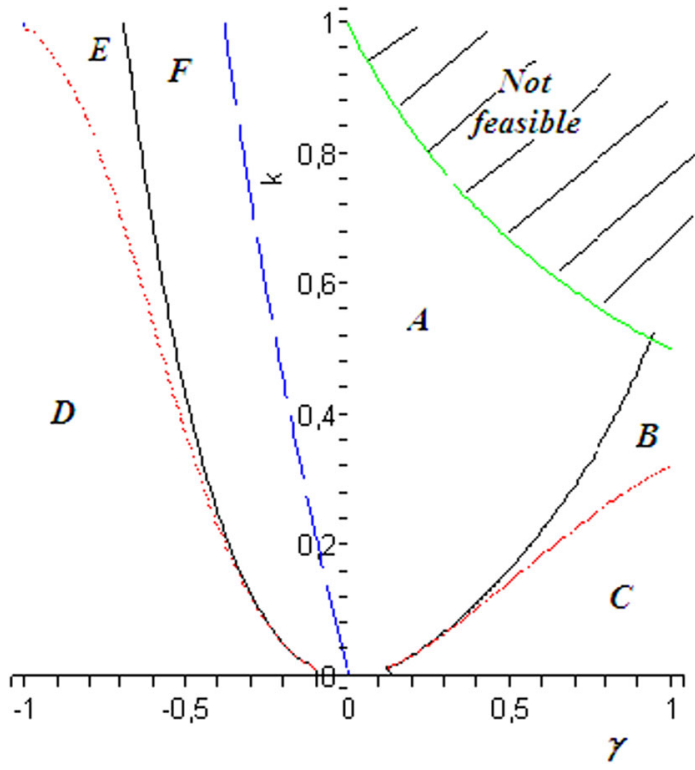

Almost perfect complements goods, i.e. $\gamma=-.99$.

Result 2 For whatever values of $k$, there exists a unique SPNE, that is (CSR, CSR), and since (CSR, CSR) payoff-dominates (PM, PM), it is also Pareto-efficient for both firms.

Proof The proof is derived directly from profit differentials (13), (14), and (15).

In the general case of heterogeneous products (i.e. $-1<\gamma<1$ ), the following holds:

Result 3 Given Eqs. (13)-(15) and the condition $\pi_{i} \geq 0$, it is possible to construct Fig. 2 in the $(\gamma, k)$-space, which has the following characteristics:

1. In region $\mathrm{A}$, the unique $\mathrm{SPNE}$ is $\mathrm{PM} / \mathrm{PM}$.

2. In regions $B$ and $E$, there are two asymmetric SPNE: PM/CSR and CSR/PM.

3. In regions $\mathrm{C}$ and $\mathrm{D}$, the unique SPNE is CSR/CSR.

4. In region $\mathrm{F}$, the unique SPNE is PM/PM.

Proof The proof is derived straightforwardly from the following inequalities: ${ }^{9}$ region A: $\Delta \pi_{1}<0, \Delta \pi_{2}>0, \Delta \pi_{3}>0$; region B: $\Delta \pi_{1}>0, \Delta \pi_{2}>0, \Delta \pi_{3}>0$; region $\mathrm{C}: \Delta \pi_{1}>0, \Delta \pi_{2}<0, \Delta \pi_{3}>0$; region $\mathrm{D}: \Delta \pi_{1}>0, \Delta \pi_{2}<0, \Delta \pi_{3}<0$; region E: $\Delta \pi_{1}>0, \Delta \pi_{2}>0, \Delta \pi_{3}<0$; region F: $\Delta \pi_{1}<0, \Delta \pi_{2}>0, \Delta \pi_{3}<0$.

\footnotetext{
${ }^{9}$ For the sake of precision, the analysis of the signs of $\Delta \pi_{1}$ and $\Delta \pi_{2}$ determines the SPNEs, while the analysis of $\Delta \pi_{3}$ determines the Pareto-efficiency (or inefficiency) of those equilibria, as below investigated in Result 4.
} 
The comments to Results 1-3 are simple. First, the rich gamma of equilibria is determined by a varying degree of product competition. In essence, when goods are substitutes, the higher (resp. lower) the product competition is, i.e. the higher (the lower) the value of $\gamma$, the more likely CSR (resp. PM or even asymmetric and multiple choices) is the SPNE. The rationale for this result is as follows: from Sect. 2.3 it is recognized that the higher the level of social engagement, the larger the output expansion of the firm and, thus, the larger the market share of the CSR firm with respect to the PM firm. Therefore, with close substitute goods, sufficiently low levels of CSR engagement favour the emergence of CSR as the SPNE, because an increasing social concern makes the unilateral deviation from PM increasingly profitable for a firm; consequently, both firms opt for the adoption of CSR rules. However, when the value of $k$ is large enough, the firm choosing CSR expands output at a level such that the rival reduces production to sustain prices and prefers PM which ensures profits higher than a CSR duopoly; thus, asymmetric equilibria arise. Finally, combinations of more independent goods and high values of $k$ lead firms to choose PM. On the other hand, with close complement goods, given the strategic complementarity, both firms mainly prefer the adoption of CSR rules.

The empirical predictions are that, in industries (1) with very differentiated products CSR behaviours should be rarely observed, (2) with intermediate values of the differentiation degree the case of one firm following CSR rules and the other profit-maximising should be more often found, and (3) at the two extremes of the substitutes/close complements, the presence of CSR firms should be more often observed.

While Result 3 provides all of the SPNEs of the game, the following result provides the welfare properties of such SPNEs:

Result 4 (1) In region A, the SPNE PM/PM is Pareto-efficient. (2) In region D, the SPNE CSR/CSR is Pareto-efficient. (3) In region C, the SPNE CSR/CSR is Paretoinefficient, and the game is a "prisoner's dilemma". (4) In region B, the asymmetric equilibrium (CSR,PM) payoff-dominates (CSR,CSR), while the asymmetric equilibrium (PM,CSR) is payoff-dominated by (PM,PM). (5) In region E, the asymmetric equilibrium (PM,CSR) payoff-dominates (PM,PM), while the asymmetric equilibrium (CSR,PM) is payoff-dominated by (CSR,CSR). (6) In region F, the SPNE PM/PM is Pareto-inefficient, and the game is a "prisoner's dilemma".

Proof The proof derives directly from Results 1-3 and the following firms' payoff structure in region E: $\pi_{2}^{C S R / P M}>\pi^{C S R / C S R}>\pi_{1}^{C S R / P M}>\pi^{P M / P M}$.

The intuition is that, following the interest of stakeholder-consumers means a more aggressive behaviour on the market; such aggressiveness, provided that it is not too intense and that the competition is fierce, may be convenient for strategic reasons for each firm. However, this leads to a typical prisoner's dilemma situation.

On the other hand, the output of the CSR firm larger than the PM one has a different effect on the market prices of the two companies. In fact, the negative impact of the aggressive behaviour of the CSR firm on its own price is higher than on that of the PM firm, and the degree of product differentiation attenuates this effect on the latter. Therefore, the presence of areas B and E in Fig. 1 seems to 
suggest that, in those portions of the $(\gamma, k)$-space the combination of the parameters is such that one firm finds profitable not to adopt CSR rules, because it may charge a relatively high price without drastically lowering output levels with respect to the CSR firm. Conversely, when competition is low and the interest for consumers is too high, no firm may find profitable to follow CSR rules. ${ }^{10}$

\section{Welfare considerations}

Let us consider the welfare effects of the model. The social welfare function (the sum of the industry profits and consumer surplus) is given by:

$$
S W=\sum \pi_{i}+C S, \quad i=1,2 .
$$

Using Eqs. (2) and (3), the relevant expressions of the three configurations CSR/ $\mathrm{CSR}, \mathrm{PM} / \mathrm{PM}$, and asymmetric regimes are $S W_{C S R}=\frac{a^{2}[3+\gamma-2 k(1+\gamma)]}{[2+\gamma-k(1+\gamma)]^{2}}, S W_{P M}=\frac{a^{2}(3+\gamma)}{(2+\gamma)^{2}}$, $S W_{\text {Asy }}=\frac{a^{2}\left[2(1-k)^{2} \gamma^{3}-\left(2-6 k+k^{2}\right) \gamma^{2}-2\left(8-7 k+2 k^{2}\right) \gamma+3 k^{2}-20 k+24\right]}{2\left[2(2-k)-\gamma^{2}(1-k)\right]^{2}}$.

A direct analytical inspection reveals the following result.

Result 5 A duopoly in which both firms adopt CSR rules always leads to the best achievable social welfare outcome.

Proof Simple comparison of the social welfare expressions reveals that, in the feasible set of the $(\gamma, k)$-space, $S W_{C S R}>S W_{\text {Asy }}>S W_{P M}$.

Given Result 5, Fig. 3 shows the relation between the firms' game equilibria and social welfare. A straightforward graphical inspection reveals that universal CSR arises as the SPNE in regions C and D, and this outcome also represents the best achievable outcome in terms of social welfare. While in region $\mathrm{C}$ universal CSR is Pareto-inefficient, in region D it is Pareto-efficient for firms. In the former case, the strategic interactions in the product market drive the result against the firms' interests; however, the socially best achievable outcome is attained. On the other hand, in the latter case, when goods are "very" complements, the firms' strategic

\footnotetext{
${ }^{10}$ In the supplement, we examine the case of the firms' non-cooperative endogenous choice of the level of social concern (i.e. the level of $k$ is totally under the control of the firms' owners and does not depend on the stakeholders). We find that, in the case of substitute goods, there exists a unique SPNE in which both firms adopt CSR and, given that PM payoff-dominates CSR, this equilibrium is Pareto-inefficient, so that a standard prisoner's dilemma emerges. On the other hand, in the case of complement goods, there are two pure-strategy asymmetric Nash equilibria, that is (CSR,PM) and (PM,CSR), and the game becomes a coordination game. In addition, in the case in which the endogenous choice of $k$ depends on the maximisation of the objective function $W$, the results are in a certain sense rather trivial. In fact, the value of the consumers' surplus dominates that of profits in the function $W$ (a well-known result in the IO literature in the presence of standard linear demand and technology). This means that the objective function $W$ is always increasing in the weight of the consumer surplus, and it reaches a maximum compatible with the non-negativity constraint condition of profits. As a consequence, not only would it be a convenient an unilateral introduction, but of CSR rules: all firms, in equilibrium, choose to introduce CSR with zero profits.
} 


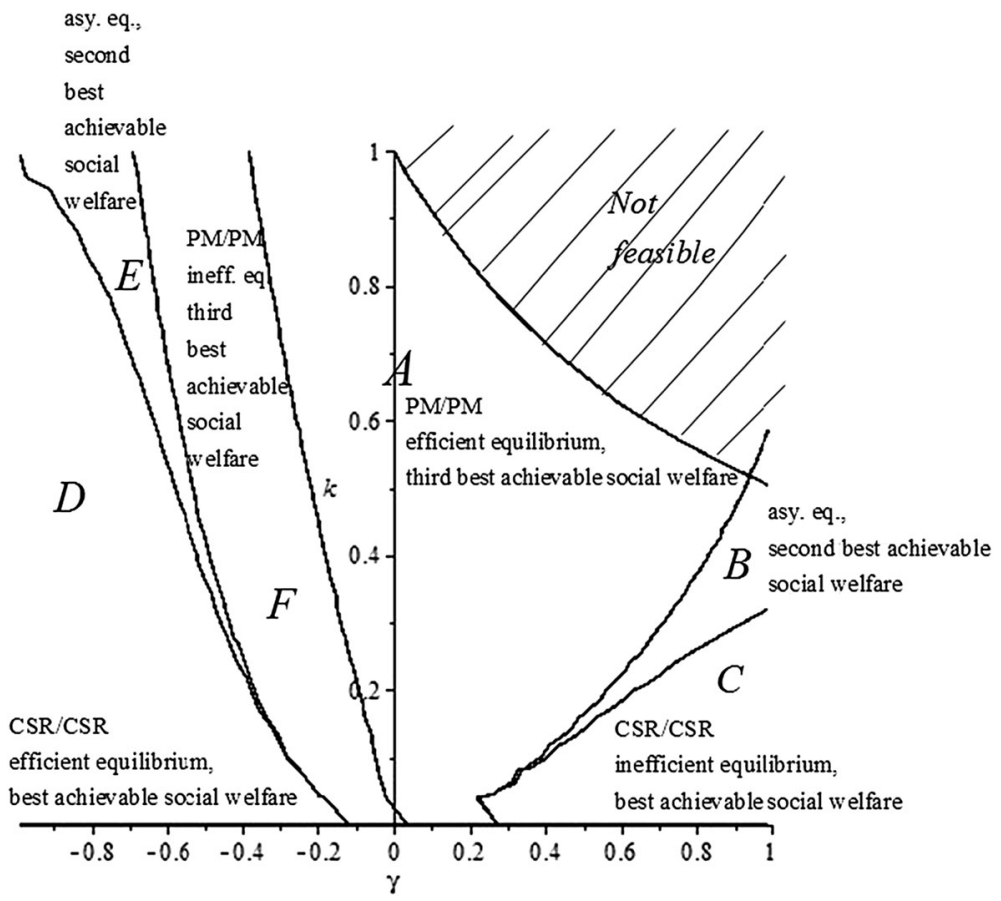

Fig. 3 Endogenous equilibria and social welfare in the $(\gamma, k)$-space. The graphs are drawn for $a=1$

interaction leads to the most desirable welfare outcome, and this is in line with the firms' interests.

Regions $A$ and $F$, in which $\mathrm{PM} / \mathrm{PM}$ emerges as endogenous equilibrium, represent the most problematic areas, because product market interactions lead the economy to the third best achievable social welfare outcome. In fact, the strategic interactions induce duopolists to select PM; nonetheless, this equilibrium is Paretoinefficient, because the universal adoption of CSR would make both firms better off, and this would be in line with the objective of a social welfare-maximising government.

These results offer the policy implication that decision makers should pay attention both to the degree of product differentiation and the level of social engagement to design the appropriate intervention tools (e.g. mandatory introduction of quality standards). However, given that the universal presence of socially concerned firms facilitates the attainment of the highest welfare level the governments should encourage the overall adoption of CSR rules. ${ }^{11}$

\footnotetext{
${ }^{11}$ In the case of the non-cooperative endogenous choice of $k$, the firms' strategic interaction with substitute goods leads to the socially best achievable outcome given by universal CSR, although this is in contrast to the firms' interests because universal PM payoff-dominates universal CSR. On the other hand, with complement goods, the firms' strategic interaction generates asymmetric equilibria which lead the economy to a second best achievable welfare outcome for a sufficiently large range of $\gamma$; however, when the goods are "very" complement, those asymmetric equilibria leads to the most desirable social welfare. These results are reported in detail in the supplement.
} 


\section{Conclusions}

Using a simple two-stage game in which duopoly firms compete à la Cournot with differentiated products, this paper investigates the firms' strategic selection in adopting CSR rules. To the best of our knowledge, the game-theoretic approach proposed here is the unique work which shows that, depending on the degree of product differentiation and firms' social concerns, in equilibrium, there are situations in which the following arise: (1) universal adoption of CSR rules: (2) the presence of only PM firms; (3) the co-existence of a CSR with a PM firm; that is, an equilibrium in which identical firms engaged in different levels of CSR may arise as simple effect of the strategic context; and (4) multiple symmetric equilibria. Therefore, grounded on a game theoretical analysis, this work can help to shed light on the rationale for the emergence, widely observed in the real world, of various equilibria in different industries, related to firms' strategic moves, in which CSR behaviours are more or less frequently widespread. With regard to welfare, the firms' strategic interaction in the product market leads to the adoption of CSR rules both in the presence of sufficiently high levels of product substitutability/complementarity, especially when the levels of social concerns are adequately low, driving the economy to the best achievable welfare outcome. In the former case, this is in contrast to firms' interests, while, in the latter, the firms' and social interests coincide. However, there exists a wide area in the relevant parameter space defined by low-medium degrees of substitutability/complementarity among products in which universal profit maximisation rule emerges in equilibrium, leading the economy to the less-desirable social welfare level. Moreover, under Bertrand competition, the SPNE is always universal PM in which the social welfare is the least desirable: this implies that, in contrast to the conventional wisdom, Bertrand may appear as welfare dominated by Cournot.

These results contribute to the increasing policy debate on firms' social concerns, showing the thus-far not fully explored effects of such concerns in shaping the industry equilibrium. However, those results call for a robustness check under different model specifications such as the presence of network effects and the presence of asymmetric and endogenous costs (such as unionised labour costs). These extensions are left for further research.

\section{Compliance with ethical standards}

Funding This study was not funded by any Institution.

Conflict of interest The authors declare that they have no conflict of interest.

Open Access This article is distributed under the terms of the Creative Commons Attribution 4.0 International License (http://creativecommons.org/licenses/by/4.0/), which permits unrestricted use, distribution, and reproduction in any medium, provided you give appropriate credit to the original author(s) and the source, provide a link to the Creative Commons license, and indicate if changes were made. 


\section{Appendix}

\section{The model with Bertrand competition}

From Eq. (1), it is possible to derive the direct market demand

$$
q_{i}=\frac{a(1-\gamma)-p_{i}+\gamma p_{j}}{1-\gamma^{2}}
$$

for $i, j=1,2$ and $i \neq j$. Given Eq. (3), when both firms follow CSR rules, substitution of Eq. (17) into Eq. (4) (in which $\pi_{i}=p_{i} q_{i}$ ) and subsequent maximisation w.r.t. $p_{i}$ leads to the following reaction functions ${ }^{12}$

$$
p_{i}\left(p_{j}\right)=\frac{a(1-k)\left[(1-\gamma)+p_{j}\right]}{2-k}
$$

Observing the reaction functions in (18), it can be noted that a socially concerned firm has an incentive to sell products at a price lower than a profit-maximising firm.

Regardless of the value of $\gamma$, as $k$ increases, the price of the socially concerned firm is reduced; the differentiation of (18) reveals that $\frac{\partial p_{i}}{\partial k}<0$ both for substitute $(\gamma>0)$ and complement $(\gamma<0)$ goods.

Figure 4 shows this result. The left box depicts the case of substitute goods: the reaction functions are upward sloping (strategic complements). The right box depicts the case of complement goods: the reaction functions are downward sloping. In this case, goods behave as when the strategies are substitutes. In both cases, the increasing weight attached to the stakeholder-consumers' interests by socially
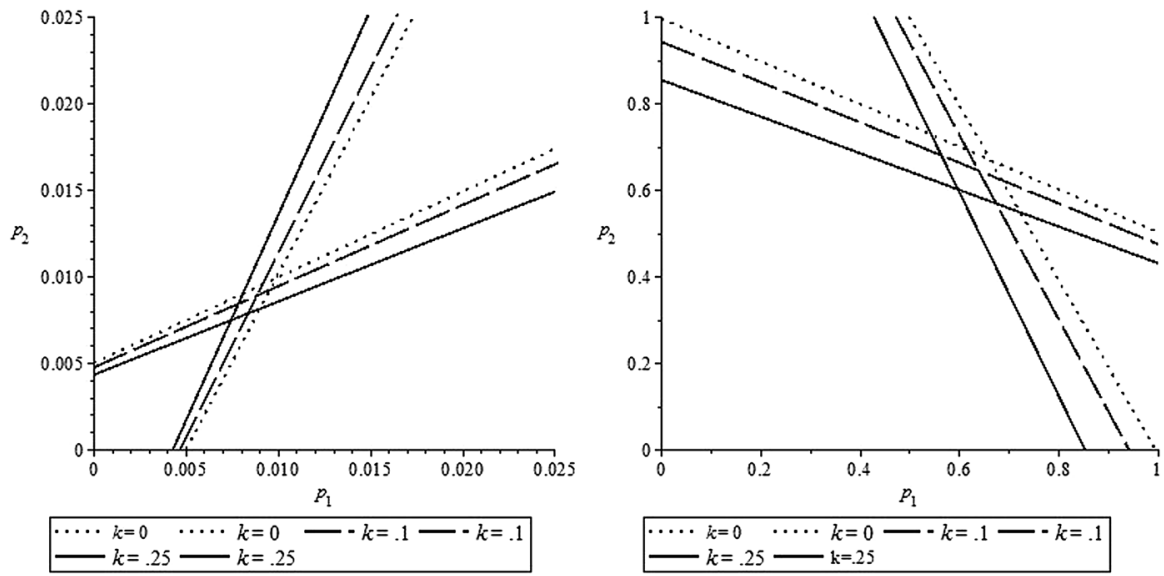

Fig. 4 Adoption of different levels of social engagement (CSR rules) and firms' reaction functions in Bertrand competition. Left box perfect substitutes $(\gamma=1)$. Right box almost perfect complements $(\gamma=-.99)$. The graphs are drawn for $a=1$

\footnotetext{
12 It can be easily verified that the second-order condition of the profit maximisation problem is satisfied.
} 
concerned firms drives more aggressive market behaviour through price reduction; however, the relative aggressiveness is weaker when goods are substitutes than complements (the price reduction for a given level of $k$ is smaller when $\gamma>0$ than when $\gamma<0$ ). Therefore, also in the case of Bertrand competition, the adoption of CSR rules implies a fiercer competition in the product market.

From (18), the equilibrium prices are

$$
p^{C S R / C S R}=\frac{a(1-k)(1-\gamma)}{[2-k-\gamma(1-k)]}
$$

Inserting Eq. (19) into Eq. (17), the equilibrium quantity in Bertrand competition is ${ }^{13}$

$$
q^{C S R / C S R}=\frac{a}{(1+\gamma)[2-k-\gamma(1-k)]}
$$

thus leading to the equilibrium profits

$$
\pi^{C S R / C S R}=\frac{a^{2}(1-\gamma)(1-k)}{(1+\gamma)[2-k-\gamma(1-k)]^{2}}
$$

On the other hand, to get all the relevant expressions when both firms are profitmaximising, one evaluates Eqs. (17)-(21) at $k=0$. Thus, the firms' profits are

$$
\pi^{P M / P M}=\frac{a^{2}(1-\gamma)}{(1+\gamma)(2-\gamma)^{2}}
$$

Finally, in the asymmetric case, one firm follows CSR and the other is profitmaximising. As in the main text, let us assume that firm $i$ maximises the social objective function in Eq. (4) (with $\pi_{i}=p_{i} q_{i}$ ), while the rival $j$ simply maximises profits $\left(k=0\right.$, therefore $\left.\pi_{j}=p_{j} q_{j}\right)$. Under these assumptions, after the application of the usual standard maximisation techniques, one gets the following equilibrium values:

$$
\begin{gathered}
p_{i}=\frac{a\left[\left(2-\gamma-\gamma^{2}\right)(1-k)\right]}{\left[2(2-k)-\gamma^{2}(1-k)\right]}, p_{j}=\frac{a\left[\left(2+k-\gamma-\gamma^{2}(1-k)\right]\right.}{\left[2(2-k)-\gamma^{2}(1-k)\right]}, \\
q_{i}=\frac{a\left(2-\gamma-\gamma^{2}\right)}{\left(1-\gamma^{2}\right)\left[2(2-k)-\gamma^{2}(1-k)\right]}, q_{j}=\frac{a\left[1-\gamma+\left(1-\gamma^{2}\right)(1-k)\right]}{\left(1-\gamma^{2}\right)\left[2+\left(2-\gamma^{2}\right)(1-k)\right]} \\
\pi_{i}^{C S R / P M}=\frac{a^{2}(1-\gamma)(1-k)(2+\gamma)^{2}}{(1+\gamma)\left[2(2-k)-\gamma^{2}(1-k)\right]}, \\
\pi_{j}^{C S R / P M}=\frac{a^{2}\left[1-\gamma+\left(1-\gamma^{2}\right)(1-k)\right]^{2}}{\left(1-\gamma^{2}\right)\left[2+\left(2-\gamma^{2}\right)(1-k)\right]^{2}}
\end{gathered}
$$

\footnotetext{
13 Under Bertrand competition, it can be easily verified that the non-negativity conditions on prices and quantities are always satisfied in the relevant parameter space.
} 


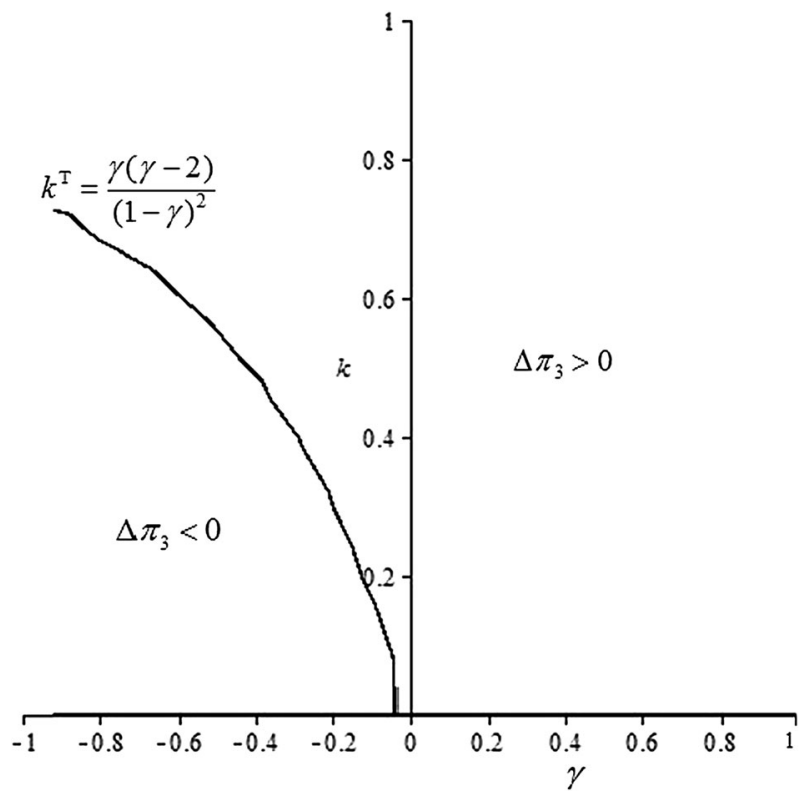

Fig. 5 Plot of the profit differential $\Delta \pi_{3}=\pi^{P M / P M}-\pi^{C S R / C S R}$ in the $(\gamma, k)$-space. The graph is drawn for $a=1, \Delta \pi_{3}=0 \Leftrightarrow k^{\mathrm{T}}=\frac{\gamma(\gamma-2)}{(1-\gamma)^{2}}$ (black solid line)

Given the outcomes in (21), (22), and (25) and defining the profit differentials $\Delta \pi_{1}=\pi_{1}^{C S R / P M}-\pi^{P M / P M}, \Delta \pi_{2}=\pi_{2}^{C S R / P M}-\pi^{C S R / C S R}, \Delta \pi_{3}=\pi^{P M / P M}-\pi^{C S R / C S R}$ as in the main text, one can directly verify that $\Delta \pi_{1}<0, \Delta \pi_{2}>0$ and $\Delta \pi_{3}>0 \Leftrightarrow$ $k>k^{\mathrm{T}}=\frac{\gamma(\gamma-2)}{(1-\gamma)^{2}}$ (see also Fig. 5). ${ }^{14}$ As a consequence, the following result holds.

Result A.1 Given that $\Delta \pi_{1}<0, \Delta \pi_{2}>0$ and $\Delta \pi_{3}>0$ for $k \frac{>}{<} k^{\mathrm{T}}$ (1) simple profit maximisation is the dominant strategy for firms; therefore, (PM, PM) is the unique SPNE (2) if $k \geq k^{\mathrm{T}}$,(PM, PM) payoff-dominates (CSR, CSR), and the equilibrium is Pareto-efficient for firm, while, if $k<k^{\mathrm{T}}$, the opposite holds true: the Nash equilibrium is Pareto-inefficient, so that a standard prisoner's dilemma emerges.

Therefore, unilateral deviation from the profit maximisation rule is always unprofitable. The reason for this result is intuitive. Under Bertrand competition, firms compete in strategic complements. The unilateral adoption of CSR rules leads the firm to expand output, with negative effects on the price and profits. Nonetheless, when the degree of complementarity among products is adequately high and the level of the social concern is not too strong, there exists an area in the $(\gamma, k)$-space in which the (CSR, CSR) equilibrium payoff-dominates the (PM, PM) equilibrium: as such, firms face a classical prisoner's dilemma situation.

\footnotetext{
${ }^{14}$ Further analytical details are available upon request from the authors.
} 


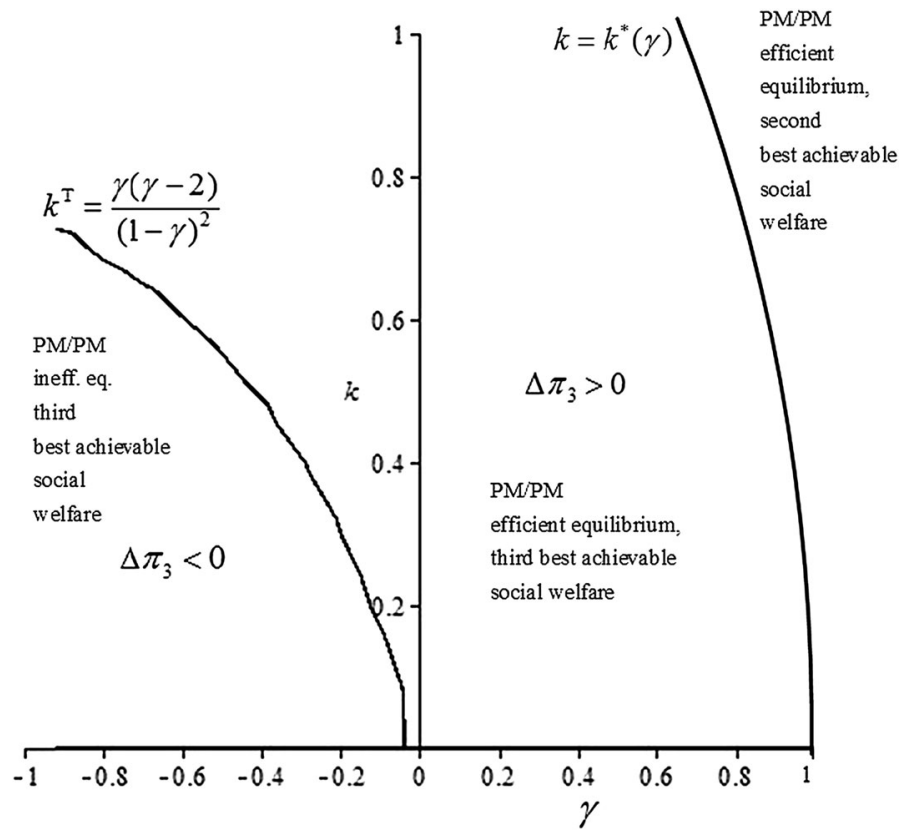

Fig. 6 Endogenous equilibria and social welfare in the $(\gamma, k)$-space, Bertrand competition. The graphs is drawn for $a=1, \Delta \pi_{3}=0 \Leftrightarrow k^{\mathrm{T}}=\frac{\gamma(\gamma-2)}{(1-\gamma)^{2}}, S W_{A s y}=S W_{P M} \Leftrightarrow k=k^{*}(\gamma)$

With regard to welfare, given (19)-(25) and the definition of social welfare in (16), the expressions of the social welfare under the three configurations CSR/CSR, $\mathrm{PM} / \mathrm{PM}$, and asymmetric regimes are

$$
\begin{gathered}
S W_{C S R}=\frac{a^{2}[3-2 \gamma-2 k(1-\gamma)]}{(1+\gamma)[2-k-\gamma(1-k)]^{2}}, S W_{P M}=\frac{a^{2}(3-2 \gamma)}{(1+\gamma)(2-\gamma)^{2}}, \\
S W_{A s y}=\frac{a^{2}\left\{(2-k)(4-3 k) \gamma-2(1-k) \gamma^{2}[(2-k) \gamma+(5-k)]+3 k^{2}-20 k+24\right\}}{2(1+\gamma)\left[2(2-k)-\gamma^{2}(1-k)\right]^{2}}
\end{gathered}
$$

An analytical inspection reveals the following result.

Result A.2 A duopoly in which both firms adopt CSR rules always leads to the best achievable social welfare outcome.

Proof Direct comparison of the social welfare expressions reveals that, in the $(\gamma, k)$ space, $\quad S W_{C S R}>S W_{A s y}>S W_{P M}$ for $k \leq k^{*}(\gamma)=\frac{2(1-\gamma)(2-\gamma)(2+\gamma)^{2}}{2 \gamma^{3}(1+\gamma)-\gamma(11 \gamma-4)+12}$, while for $k>k^{*}(\gamma)$, the ranking is $S W_{C S R}>S W_{P M}>S W_{A s y}$.

Given Result A.2, Fig. 6 depicts the relation between the firms' endogenous game equilibria and social welfare. The firms' strategic interactions in the product market lead to universal PM (see Result A.1), and this outcome represents the third 
best achievable result in terms of social welfare for a large area of the parameter set. Therefore, by comparing Figs. 3 and 6, we may observe that the best achievable welfare outcome is more likely under Cournot than Bertrand. Because CSR emerges as an equilibrium under Cournot but never under Bertrand, then, in contrast to the conventional wisdom, Bertrand may appear as welfare dominated by Cournot.

\section{References}

Allaz, B., \& Vila, J. L. (1993). Cournot competition forward markets and efficiency. Journal of Economic Theory, 59(1), 1-16.

Bagnoli, M., \& Watts, S. G. (2003). Selling to socially responsible consumers: Competition and the private provision of public goods. Journal of Economics and Management Strategy, 12(3), 419-445.

Baron, D. (2001). Private politics, corporate social responsibility, and integrated strategy. Journal of Economics and Management Strategy, 10, 7-45.

Baron, D. (2009). A positive theory of moral management, social pressure, and corporate social performance. Journal of Economics and Management Strategy, 18, 7-43.

Benabou, R., \& Tirole, J. (2010). Individual and corporate social responsibility. Economica, 77, 1-19.

Bennett, J., Iossa, E., \& Legrenzi, G. (2003). The role of commercial non-profit organizations in the provision of public services. Oxford Review of Economic Policy, 19, 335-347.

Benz, M. (2005). Not for profit, but for satisfaction? Evidence on worker well-being in non-profit firms. Kyklos, 58, 155-176.

Besley, T., \& Ghatak, M. (2007). Retailing public goods: The economics of corporate social responsibility. Journal of public Economics, 91(9), 1645-1663.

Bulow, J. I., Geanakoplos, J. D., \& Klemperer, P. D. (1985). Multimarket oligopoly: Strategic substitutes and complements. Journal of Political Economy, 93(3), 488-511.

Fanti, L., \& Buccella, D. (2016). The effects of corporate social responsibility on entry. Economia $e$ Politica Industriale. doi:10.1007/s40812-016-0029-6. (First online: 17 Feb 2016, forthcoming).

Fershtman, C., \& Judd, K. L. (1987). Equilibrium incentives in oligopoly. American Economic Review, 77(5), 927-940.

García-Gallego, A., \& Georgantzís, N. (2009). Market effects of changes in consumers' social responsibility. Journal of Economics and Management Strategy, 18(1), 235-262.

Goering, G. E. (2007). The strategic use of managerial incentives in a non-profit firm mixed duopoly. Managerial and Decision Economics, 28, 83-91.

Goering, G. E. (2008). Welfare impacts of a non-profit firm in mixed commercial markets. Economic Systems, 32, 326-334.

Kopel, M., \& Brand, B. (2012). Socially responsible firms and endogenous choice of strategic incentives. Economic Modelling, 29(3), 982-989.

Kotchen, M. J. (2006). Green markets and private provision of public goods. Journal of Political Economy, 114(4), 816-834.

KPMG, 2011. KPMG survey of corporate responsibility reporting 2013. https://www.kpmg.com/PT/pt/ IssuesAndInsights/Documents/corporate-responsibility2011.pdf. Accessed 13 Sept 2015.

KPMG, 2015. Currents of Change: KPMG Survey of Corporate responsibility reporting 2015. http://www.kpmg.com/cn/en/issuesandinsights/articlespublications/pages/kpmg-survey-of-corporateresponsibility-reporting-2015-o-201511.aspx. Accessed 13 Sept 2015.

Lambertini, L., \& Tampieri, A. 2010. Corporate social responsibility in a mixed oligopoly. Department of Economics, University of Bologna. Working paper 723.

Mahenc, P., \& Salanié, F. (2004). Softening competition through forward trading. Journal of Economic Theory, 116, 282-293.

Porter, M. E., \& Kramer, M. R. (2006). Strategy and society: The link between corporate social responsibility and competitive advantage. Harvard Business Review, 84(12), 78-92.

Reinhardt, F. L., \& Stavins, R. N. (2010). Corporate social responsibility, business strategy, and the environment. Oxford Review of Economic Policy, 26(2), 164-181. 
Reputation Institute, 2015. 2015 Global CSR RepTrak 100. http://www.reputationinstitute.com/ CMSPages/GetAzureFile.aspx?path= \medialmedialdocuments 2015 -global-csr-reptrak-results.pdf \&hash=f375854351576541 ae88db1e043e7417e9f057f83955bb3768454dd8e0417353\&ext=.pdf. Accessed 17 Sept 2015.

Schiff, J., \& Weisbrod, B. (1991). Competition between for-profit and non-profit organizations in commercial markets. Annals of Public and Cooperative Economics, 62, 619-639.

Spitzeck, H., \& Hansen, E. G. (2010). Stakeholder governance: How stakeholders influence corporate decision making. Corporate Governance: The International Journal of Business in Society, 10(4), 378-391. 